\title{
Claude Lévi-Strauss, fundador del pos-estructuralismo
}

\author{
Eduardo Viveiros de Castro \\ Museo Nacional, Rio de Janeiro, Brasil
}

\begin{abstract}
N. de R. En homenaje al recientemente fallecido antropólogo francés Claude Lévi-Strauss, nos complacemos en publicar el texto de la conferencia ofrecida por el Dr. Eduardo Viveiros de Castro, funcionario del Museo Nacional de Río de Janeiro, con motivo del Coloquio: LéviStrauss: un siglo de reflexión. El coloquio en referencia tuvo lugar en la ciudad de México hace un año, el 19 de noviembre del 2008, cuando precisamente ese día el homenajeado cumplía un siglo de vida. El discurso del Dr. Eduardo Viveiros, propiciado por los cientificos sociales mexicanos, tiene por eso doble significación: es un memorable homenaje a un pensador representativo del siglo XX, como filósofo y etnólogo, fundador del estructuralismo que cumple cien años de existencia y es ofrecido por un intelectual brasileño, país donde Lévi-Strauss se inició como antropólogo de fecunda creación y poderosa influencia en distintas disciplinas del pensamiento moderno.
\end{abstract}

Estimados colegas,

Debo comenzar diciendo que estoy muy emocionado por el honor que se me hace aquí, al invitarme a abrir con esta alocución el Coloquio Lévi-Strauss: un siglo de reflexión. No consigo explicarme que me hayan escogido, entre tantos colegas aquí reunidos -todos con mejores credenciales que yo para esa distinción-, salvo por la contingencia de ser un etnólogo nacido en Brasil, y que estudia pueblos indígenas brasileños. Así, veo en esta invitación una especie de homenaje indirecto a mi país, donde Lévi-Strauss hizo sus primeras armas como etnólogo, pero sobre todo a los pueblos indígenas brasileños, pueblos cuyo pensamiento, al contribuir de modo decisivo a formar el del propio Lévi-Strauss, llegó por fin a irrigar la tradición filosófica de Occidente después de cinco siglos de olvido o desprecio, en el preciso momento en que esa tradición necesita como nunca toda la ayuda externa que pueda conseguir. Pues finalmente, el Occidente empieza a comprender que no pasó de ser un accidente, un gigantesco accidente antropológico que podrá concluir cerrar la carrera de la especie sobre la Tierra.

La segunda razón que se me ocurre para explicar tan distinguida invitación sería por así decirlo intrínsecamente lévi-straussiana o estructuralista, a saber: me han llamado a hablarles porque, como pueden percibir, yo no hablo la lengua de ustedes, sino una lengua gemela de ella. Sabemos que la característica fundamental de los gemelos en la mitología 
amerindia es ser ligeramente, pero crucialmente, desiguales, asimétricos. Esa asimetría es palpable en el caso de nuestras lenguas, en el que el portugués desempeñaría el papel de gemelo lunar, menor, con algo de engañador (de decepteur, trickster) en su vocalismo nasal y elusivo, sus diptongos traidores, en contraposición al español solar, cristalino, robusto y magnífico, que sería el gemelo mayor, el demiurgo de la pareja. Lo que ustedes están oyendo en este momento, por lo tanto, es el engañador (el tlacuache o el coyote) tratando de hacerse pasar por el demiurgo (el jaguar o el lince), como sucede en tantos mitos del continente. En los mitos de Amazonía al menos, el primero siempre fracasa, de un modo, al mismo tiempo, cómico y grotesco.

Comoquiera que sea, esta conferencia se coloca por entero bajo el signo de los gemelos, ya que éstos son, como dice algo enigmáticamente Lévi-Strauss en su libro más profundo -me refiero a Histoire de Lynx-, "la clave de todo el sistema". El maestro francés se refiere aquí al sistema mítico panamericano analizado en la serie de las Mitológicas; pero yo me refiero al sistema teórico del estructuralismo. Si es que es realmente posible distinguir los dos sistemas.

\section{II}

El título que irresponsablemente se me ocurrió dar a esta conferencia es "Claude LéviStrauss, fundador del posestructuralismo". Temo que es necesario justificarlo. Para eso, empezaré por hablar de otro título. Hace pocos días terminé de escribir un libro sobre LéviStrauss que se titula Isso não é tudo: Lévi-Strauss e a mitologia ameríndia "Eso no es todo: Lévi-Strauss y la mitología amerindia". "Eso no es todo", "ce n'est pas tout" es una fórmula que el autor emplea con mucha frecuencia, especialmente en las Mitológicas, al punto de que podríamos considerarla como un manierismo diacrítico. La "pequeña frase de LéviStrauss" (la llamo así en homenaje a la "petite phrase de Vinteuil" de En busca del tiempo perdido), marca el surgimiento casi prestidigitatorio de otro eje más, siempre "otro eje" de transformación, colocado de través, en diagonal a los varios ejes que hasta ahí venían guiando la comparación; anuncia la presencia de una torsión suplementaria totalmente imprevista, que abre súbitamente una progresión de lo que estaba encaminado hacia su cierre; señala la revelación de un vínculo adicional, implicado, oscuro, compactado en el texto que se está analizando, que súbitamente se explica y se aclara, y al mismo tiempo se multiplica y se difracta en perspectivas que, literalmente, se pierden de vista en el horizonte.

El movimiento que la pequeña frase señala ocurre con mucho más frecuencia que esta; ella es opcional, pero el movimento nos parece necesario, intrínseco al procedimiento lévistraussiano, procedimiento que jamás termina, al contrario de lo que perezosamente se acostumbra a enseñar, con el establecimiento de oposiciones binarias; en verdad, comienza en ellas, y comienza por complicarlas. Recordemos sobre todo la profunda observación del "Finale" de L’homme nu (pp. 539-40): "El problema de la génesis del mito se confunde con el del pensamiento mismo, cuya experiencia constitutiva no es la de una oposición entre el yo y el otro, sino la del otro aprehendido como oposición." De donde se puede concluir, en sintonía con otros pasajes del autor, que el yo es un caso particular del otro, así como la oposición, tanto como la identidad, es apenas un caso particular de la diferencia.

Para nuestro autor, en efecto, una oposición binaria es cualquier cosa menos un objeto simple, o simplemente doble, o siquiera simplemente un objeto; tal vez ni siquiera -pero aquí es posible que estemos yendo demasiado lejos- una oposición. Léanse las páginas luminosas del Origen de las maneras de mesa o de la Alfarera celosa sobre la naturaleza exacta, o más bien "anexacta", de la relación entre el Sol y la Luna en la mitología amerindia, y se tendrá una idea de lo que quiero decir. 
La petite phrase en realidad cumple una función conceptual fundamental dentro de la economía teórica del estructuralismo. Apunta a la perpetua inconclusión del análisis estructural, sugiriendo además que la razón de esa inconclusión es la multiplicidad virtual de todo objeto determinado por el análisis estructural, en la medida en que este objeto es siempre un estado particular de un sistema de transformaciones cuyos límites son radicalmente contingentes, y definibles únicamente en forma relacional. La "in-terminabilidad", en los dos sentidos ( sin fin o término, y sin posibilidad de determinación unívoca de lo que es un término y una relación), del análisis mítico es un principio fundamental de las Mitológicas, enunciado de inmediato al inicio de Lo crudo y lo cocido: el carácter abierto, intensivo, iterativo, en nebulosa, poroso, "conexionista" de los sistemas míticos que reconstruye. "Eso no es todo", entonces, porque nada es todo, en ningún momento se alcanza una totalización. "Eso no es todo" proyecta un concepto de estructura (y una concepción del análisis) que no privilegia ninguna voluntad de clausura, completamiento, compacidad. Con "eso no es todo" comenzamos a vislumbrar la posibilidad de un Lévi-Strauss posestructuralista.

Naturalmente, eso realmente no es todo... La pequeña frase, como una llave, puede ser usada tanto para abrir lo que estaba cerrado como para cerrar lo que estaba abierto. La demostración del cierre transformacional, de la coherencia y homogeneidad de los grupos de mitos en análisis aparece repetidas veces en el correr del texto, y alcanza una especie de apoteosis enfática en el capítulo "El mito único" de El hombre desnudo. Lévi-Strauss insistirá repetidas veces en las Mitológicas sobre el cierre, la clausura del sistema que analiza, la redondez de la tierra de la mitología, la completitud del círculo que lo lleva de las sabanas de Brasil Central a las costas brumosas del estado de Washington y de Columbia Británica, así como sobre los varios cierres de subgrupos míticos internos a ese periplo. La idea de cierre, clausura, clôture parece por momentos consustancial al análisis estructural: es necesario demostrar que el grupo se cierra, que se ha regresado al estado inicial de una cadena de mitos por una última transformación. Esa insistencia está ligada al tema de la necesaria redundancia del lenguaje mítico, condición del establecimiento de una "gramática" de la mitología, como a veces el autor se complace en concebir su empresa; y es conocida la antipatía que siente por el concepto de "obra abierta".

Ocurre, sin embargo, que la multiplicación de las demostraciones de clausuras produce la impresión paradojal de un número teóricamente indefinido, es decir, abierto, de estructuras cerradas. Las estructuras se cierran, pero el número de estructuras, y de vías por donde cerrarlas, está abierto: no hay una estructura de estructuras, en el sentido de un nivel final de totalización estructural, ni una determinación a priori de los ejes semánticos (los códigos) movilizados en estructura. ${ }^{1}$ Todo "grupo" de mitos termina por revelarse como situado en la intersección de un número indeterminado de otros grupos; y dentro de cada grupo, cada "mito" es igualmente una interconexión; y dentro de cada mito... los grupos deben poder cerrarse (clore); pero el analista no puede dejarse encerrar (enfermer) dentro de ellos: "lo propio de cada mito o grupo de mitos es prohibir que nos encerremos en él: siempre llega un momento, en el curso del análisis, en el que se plantea un problema cuya resolución obliga a salir del círculo que el análisis había trazado" (1971: p. 538).

Será preciso entonces insistir, nosotros, sobre las tensiones internas al pensamiento de Lévi-Strauss acerca de la mitología americana, a saber, sobre una dialéctica de la apertura y el cierre analítico (como el autor hablaba de una "dialéctica de la apertura y

1 La inexistencia de una metaestructura se ha señalado desde la "Introduction à l'œuvre de Marcel Mauss" y "La notion de structure en ethnologie". Sobre la indeterminación de principio de los ejes semánticos de un sistema mítico, cf. la máxima de La pensée sauvage de que "le principe d'une classification ne se postule jamais" ["el principio de una clasificación no se postula nunca"]". 
del cierre" tematizada por los mitos) que cabe explorar, inclusive en sus tentativas, tal vez necesariamente fracasadas, de auto-mediación. Necesidad o contingencia, completitud o inconclusión, estructura o multiplicidad, trascendencia de la regla o inmanencia del sentido: esa cuádruple tensión estructura el estructuralismo, y traza las líneas de divergencia de su posteridad. Es esa tensión lo que me llevó a escoger el título de esta conferencia. Porque si Rousseau, según dice Lévi-Strauss, debe ser visto como el fundador de las ciencias humanas, entonces del propio Lévi-Strauss habría que decir que no sólo las refundó, con el estructuralismo, sino que las "infundó" virtualmente, al señalar el camino hacia un posestructuralismo, o en otras palabras, hacia una antropología de la inmanencia, en la que tal vez él "como Moisés conduciendo a su pueblo a una tierra prometida cuyo esplendor él jamás contemplaría" (éste es Lévi-Strauss hablando sobre Mauss), nunca llegó a penetrar. ${ }^{2}$

\section{III}

La gran cuestión que se abre hoy, en el proceso de reevaluación -ya estaba escribiendo rehabilitación-de la herencia intelectual de Lévi-Strauss es la de decidir si el estructuralismo es uno o múltiple, o, para emplear una polaridad lévi-straussiana, si es continuo o discontinuo. Sin dejar de concordar con los intérpretes que concuerdan con Lévi-Strauss, es decir, que ven su obra como marcada por una profunda unidad de inspiración y de método, veo la personalidad teórica de su autor como dividida (pero no opuesta) en dos gemelos eternamente desiguales, un héroe cultural y un seductor, el personaje de la mediación (pero que es también el instaurador de lo discreto y del orden) y el contrapersonaje de la separación (que, sin embargo, es también el maestro del cromatismo y del desorden). Hay sí dos estructuralismos, pero como el propio Lévi Strauss mostró, dos es siempre muchos.

Así veo la obra de Lévi-Strauss, por el lado de la contingencia, de la inconclusión y de la multiplicidad: un estructuralismo en desequilibrio perpetuo. Igual que la mitología indoamericana, que supo comprender mejor que ningún otro antropólogo, esa obra es compleja, ambigua y plural, y por lo tanto siempre actual. Esa actualidad permanente de la obra es, finalmente -su capacidad de auto-desfasaje- lo que hace poco fue reconocido por la canonización según la fórmula indígena (quiero decir francesa) consagrada, que es la publicación en la Bibliothèque de la Pléiade, cuyo nombre además abunda en resonancias lévi-straussianas. Recordemos que la constelación epónima es un signo eminente de lo continuo en el pensamiento indoamericano: se ve entonces la sutileza de la "doble torsión" que condujo el gran analista del pasaje de lo continuo a lo discreto de vuelta a lo continuo; pero, en la típica marcha en espiral de la transformación mítica, a un continuo segundo, sobrenatural más que natural, un continuo cuya relativa indiferenciación interna sólo lo hace destacar más claramente en el vasto cielo nocturno y anónimo de la historia.

Y eso, una vez más, no es todo. Honor supremo, esa ascensión a lo continuo se hace en vida, en el propio año del centenario de Lévi-Strauss que ahora celebramos. Todos los antropólogos del mundo debemos sentirnos orgullosos por el homenaje que así se presta a nuestra disciplina en la persona de su más ilustre practicante, el pensador que refundó la antropología, al desmontar los fundamentos metafísicos del colonialismo occidental, y que al mismo tiempo revolucionó la filosofía, al abrir uno de los principales caminos del siglo para el desmontaje de los fundamentos colonialistas de la metafísica occidental.

2 "Il doit y avoir quelque part un passage décisif que Mauss n'a pas franchi... ['debe haber en alguna parte un pasaje decisivo que Mauss no superó']” (L.-S. 1955: xxxvii). 


\section{IV}

Se trata entonces, hoy, de saber si la antropología estructural, en flagrante discrepancia con las configuraciones simbólicas cuyos fundamentos él supo exponer tan bien, es realmente el sistema conceptual cerrado, unívoco, homogéneo y equilibrado que nos ha legado la vulgata antropológica. Bien entendido, yo pienso que no. Hoy empieza a verse claramente que la complejidad teórica del estructuralismo nunca fue íntegramente asimilada por la antropología, y que la fase de las lecturas simplificadoras de la obra de Lévi-Strauss -simplificación dialécticamente necesaria, sin duda, para el florecimiento de nuevos temas y problemas (y para la resurrección de algunos muy viejos) en la antropología de los últimos treinta años- esa fase se acerca a su fin.

Empezamos, en efecto, a darnos cuenta de que la obra de Lévi-Strauss colabora activamente, y eso desde sus comienzos, con mucho de lo que parecería ser su subversión futura, y que el estructuralismo siempre fue "gemelo de sí mismo", para recordar la interpretación de la "sentencia fatídica" que es el tema de un capítulo de Histoire de Lynx. Si Lévi-Strauss no es el último pre-estructuralista (lejos de ello, hélas!), está en cambio muy cerca de ser el primer posestructuralista.

Tomemos por ejemplo la idea-maestra, afirmada en su Lección Inaugural en el Collêge de France en 1960, según la cual la antropología utiliza "un método... más de transformaciones que de fluxiones", con lo que el autor señalaba su preferencia por una concepción de la estructura antes combinatoria que diferencial. A lo largo de la obra de Lévi-Strauss esa idea se fue convirtiendo en una verdad bastante aproximada, puesto que la noción-clave de transformación fue ella misma transformándose. Primero fue ganando precedencia semántica sobre el concepto de estructura. Segundo, fue adoptando un ropaje cada vez más analógico, cada vez más cercano a las fluxiones dinámicas, antes que a las permutaciones algebraicas. El punto de inflexión de esa curva se sitúa, según todo indica, en algún momento de la redacción de las Mitológicas. Una nota en Du miel aux cendres es tal vez el primer registro explícito del cambio:

Leach nos ha reprochado [...] recurrir exclusivamente a esquemas binarios. Como si la noción misma de transformación, que empleamos tan constantemente después de tomarla de d'Arcy Wentworth Thompson, no participase por entero de la analogía... (Lévi-S. 1966: p. 74 n. 1)

Dos décadas más tarde, el autor reafirma el punto: el concepto de transformación no le llegó de la lógica ni de la lingüística (ni, nos da la impresión, del estructuralismo matemático de Bourbaki), sino del naturalista D'Arcy Thompson, y por él, de Goethe y de Dürer (Lévi Strauss \& Eribon 1988: p. 158-59). La transformación es ahora una operación estética y dinámica, ya no lógica y algebraica. Con eso, la oposición entre ciertos paradigmas conceptuales dentro de la fase clásica del estructuralismo, como totemismo, mito, discontinuidad versus sacrificio, rito, continuidad, se vuelve mucho más fluida e inestable de lo que el autor continuará, sin embargo, afirmando en algunos pasajes de la fase posterior de su obra, como en el célebre contraste entre mito y rito del "Finale" de L'homme nu.

La línea de corte pasa claramente entre el álgebra finitaria adecuada a los contenidos del parentesco y la forma intensiva del mito:

El problema planteado en Las estructuras elementales del parentesco derivaba directamente del álgebra y de la teoría de los grupos de sustitución. Los planteados por la mitología, parecen indisociables de las formas estéticas que los objetivan. Ahora bien, éstas pertenecen a la vez a lo continuo y a lo discontinuo... (L.-S. \& Eribon 1988: p. 192) 
Lévi-Strauss menciona entonces la teoría de las catástrofes de R. Thom, que fue puesta en comunicación con el estructuralismo por Jean Petitot, un filósofo de formación matemática. La teoría de Thom, continúa Lévi-Strauss en el pasaje mencionado, permitiría superar la antinomia entre lo continuo y lo discontinuo, proponiéndose por lo tanto como la matemática adecuada para el mito.

No tengo competencia para juzgar esa adecuación o inadecuación. Pero la conclusión general que se puede extraer es que el concepto estructuralista de transformación sufrió de hecho una doble transformación, histórica y estructural; en realidad, una única transformación compleja, que la transformó en una operación simultáneamente "histórica" y "estructural". Como argumenta mi colega Mauro Almeida en un notable artículo reciente, lo que la fórmula canónica describe es precisamente la transformación de historia en estructura y viceversa (pero el camino no es el mismo en los dos sentidos): ese cambio se debe en parte a la influencia, sobre Lévi-Strauss, de las nuevas interpretaciones matemáticas disponibles; pero sobre todo, en mi opinión, al cambio del tipo de objeto privilegiado por su antropología. Con el mito, las fronteras entre permutación sintáctica e innovación semántica, desplazamiento lógico y condensación morfogenética, se volvieron más tortuosas, más contestadas, más complicadas: más fractales. La oposición entre la forma y la fuerza (las transformaciones y las fluxiones) perdió sus contornos, y en cierto modo se debilitó.

Eso no significa que Lévi-Strauss dé gran importancia a ese cambio, ni que se detenga mucho en él, más allá de la reflexión citada más arriba con respecto a los diferentes problemas tratados por el método estructural. Al contrario, siempre tendió a subrayar "la continuidad del programa que seguimos metódicamente desde Las estructuras elementales del parentesco" (la advertencia está en la "Obertura" de Lo crudo y lo cocido). Continuidad: he ahí un concepto ambivalente como pocos, en el vocabulario estructuralista...

Es claro que Lévi-Strauss tiene razón; sería un poco ridículo querer corregirlo con respecto a sí mismo, como parecen hacer algunos de sus comentaristas más fundamentalistas (iporque existe un estructural-fundamentalismo!). Pero la insistencia del maestro francés en la unidad de inspiración de su obra no nos impide proponer, como buenos estructuralistas, una lectura discontinuista de esa obra; no tanto para insistir en rupturas unívocas como para sugerir una coexistencia compleja o una superposición intensiva de estados del discurso estructural.

Las discontinuidades del proyecto estructuralista pueden distribuirse en las dos dimensiones clásicas: en el eje de las sucesiones, con la idea de que la obra de Lévi-Strauss conoce fases; y en el eje de las coexistencias, con la idea de que enuncia un discurso doble, describe un doble movimiento. Las dos discontinuidades coexisten en la medida en que los momentos de la obra se distinguen por la importancia concedida a cada uno de los dos movimientos que se oponen contrapuntísticamente a lo largo de toda ella.

\section{V}

Comencemos por la diacronía, diciendo que el estructuralismo es como el totemismo: nunca existió. O más precisamente, como el totemismo, su modo de existencia no es el de las sustancias sino el de las diferencias. En este caso, la diferencia, varias veces señalada por los comentaristas, entre la primera fase de la obra de Lévi-Strauss, representada por Las estructuras elementales del parentesco, y que se podría calificar de pre-estructuralista, y la segunda fase, posestructuralista, poblada por las Mitológicas y las tres monografías subsecuentes. 
Digo que la segunda fase es pos-estructuralista porque antes de ella se inscribe el breve momento indiscutiblemente "estructuralista", representado por los dos estudios sobre el problema totémico, que según el autor, señalan una pausa entre Las estructuras elementales y las Mitológicas. Es en los libros de 1962, en efecto, que Lévi-Strauss identifica el pensamiento salvaje, es decir, las condiciones concretas de la semiosis humana, como una gigantesca y sistemática empresa de ordenamiento del mundo, y promueve el totemismo, antiguo emblema antropológico de la irracionalidad primitiva, a modelo de toda actividad racional. A ese momento de la obra es que parece aplicarse mejor un juicio malicioso de Deleuze y Guattari (1981: 289): "El estructuralismo es una gran revolución, el mundo entero se vuelve [devient] más razonable". Un espíritu conciliador podría ponderar que, con el estructuralismo, el mundo no se vuelve más razonable sin que la razón se convierta en otra cosa... más mundana quizás, en el sentido de más secular, más popular. Más artista también, más bohemia (más surrealista), menos rentable. (Recordemos que lo contrario del "pensamiento salvaje" es el pensamiento "domesticado con miras a obtener un rendimiento").

La idea de que Las estructuras elementales del parentesco es un libro "pre-estructuralista" debe ser tomada, por supuesto, con una buena dosis de sal. De todas maneras, creo que antropólogos como David Schneider o Louis Dumont están en lo cierto al clasificar así la obra de 1949, que está efectivamente organizada en torno a las dos dicotomías fundacionales de las ciencias humanas, Individuo y Sociedad, por un lado -el problema de la integración y totalización sociales-, y por el otro Naturaleza y Cultura: el problema del instinto y de la institución humanos. Hobbes y Herder, digamos, o Durkheim y Boas; o también, la Ilustración y el Romanticismo. (Mediando esas polaridades, naturalmente, está Rousseau, ese trickster filosófico que Lévi-Strauss, no por acaso, escogió como su santo patrono...)

El problema de Las estructuras elementales... es el problema "antropológico" por excelencia de la hominización: el surgimiento de la síntesis de la cultura como trascendencia de la naturaleza. "El grupo", es decir, la Sociedad, se mantiene como sujeto trascendental y causa final de todos los fenómenos analizados. Eso, bien entendido, hasta el último capítulo del libro, en que, como señala Maniglier (uno de los más originales comentaristas de LéviStrauss que conozco), de repente todo parece disolverse en la contingencia:

las múltiples reglas que prohíben o prescriben ciertos tipos de cónyuges, y la prohibición del incesto que las resume todas, se aclaran a partir del momento en que se postula que es necesario que la sociedad exista [sea, soit]. Pero la sociedad habría podido no existir. (L.-S. 1949/1967: p. 561)

Y sigue el grandioso desarrollo conclusivo, en el que se establece al mismo tiempo que la sociedad es coextensiva al pensamiento simbólico y no su causa antecedente o su razón de ser, que la sociología del parentesco es una rama de la semiología (todo intercambio es intercambio de signos, es decir, de perspectivas), y que todo orden humano trae dentro de sí un permanente impulso de contra-orden. Esos postreros acordes marcan la entrada, todavía atenuada, de lo que podríamos llamar segunda voz del discurso antropológico de Lévi-Strauss, cuando la sociología del parentesco empieza a abrir espacio para una "antisociología", ${ }^{3}$ es decir para una economía cosmopolítica; dicho de otro modo, para el régimen del plano de inmanencia indoamericano que será trazado en las Mitológicas.

Porque es con las Mitológicas que la inversión en el orden de las voces se completa, o más bien, casi se completa; en realidad no habría sido necesario ir más lejos: como Moisés y la Tierra Prometida... En las Mitológicas, el concepto de sociedad es abandonado analíticamente, en favor de un foco sistemático en las transformaciones narrativas

3 Jacques Donzelot, sobre L'Anti-CEdipe. 
intersocietarias; la oposición Naturaleza/Cultura deja de ser una condición antropológica universal (objetiva o subjetiva) para transformarse en un tema mítico, interno al pensamiento indígena -tema cuya ambivalencia dentro de ese pensamiento, por lo demás, no hará sino aumentar en cada volumen de la serie-; y los objetos algebriformes llamados "estructuras" adquieren contornos más fluidos, derivando, como hemos visto, hacia una concepción analógica de transformación. Las relaciones que constituyen las narrativas amerindias, más que formar totalidades combinatorias en distribución discreta, en variación concomitante y tensión representacional con los realia socio-etnográficos, ejemplifican en un grado que podría decirse de verdadera ejemplaridad los principios de "conexión y heterogeneidad", "multiplicidad", "ruptura asignificante" y "cartografía" que Deleuze y Guattari contrapondrán a los modelos estructurales en nombre del célebre concepto de "rizoma": rizoma, el concepto mismo de la antiestructura, el emblema del posestructuralismo.

El movimiento de la demostración de las Mitológicas, en efecto, es el de una conectividad heterogenética generalizada, en que un mito de un pueblo transforma un ritual de un segundo pueblo y una técnica de un tercer pueblo; en que la organización social de unos es la pintura corporal de otros (o como ir de la cosmología a la cosmética sin dejar la política), y en que la redondez geométrica de la tierra de la mitología es constantemente cortocircuitada por su porosidad geológica, gracias a la cual las transformaciones parecen saltar entre puntos extremos del continente americano, surgiendo aquí y allá como afloramientos volcánicos de un océano subterráneo de magma. Acción a distancia.

Pierre Clastres ha dicho que el estructuralismo es "una sociología sin sociedad"; si esto es verdad -Clastres lo decía para criticarlo-, entonces en las Mitológicas tenemos un estructuralismo sin estructura; lo digo para alabarlo. Todo el que se disponga a hacer la travesía completa de las Mitológicas constatará que la mitología amerindia cartografiada por la serie no evoca la estructura arborescente, sino la red rizomática: es una gigantesca telaraña sin centro ni origen, un mega-agenciamiento colectivo e inmemorial de la enunciación dispuesto en un "hiperespacio" (L.-S. 1967: p. 84) incesantemente atravesado por "flujos semióticos, flujos materiales y flujos sociales" (D.G. 1981: p. 33-34); una red o un rizoma recorrido por diversas líneas de estructuración, pero que, en su multiplicidad in-terminable y su radical contingencia histórica, es irreductible a una ley unificadora e irrepresentable por una metaestructura. Existen innumerables estructuras en los mitos amerindios, pero no hay una estructura del mito amerindio; no hay, obsérvese bien, estructuras elementales de la mitología.

La mitología, en fin, es una multiplicidad abierta, una "multiplicidad a $n-1$ ", para usar el concepto de Deleuze y Guattari, o diríamos mejor a " $M_{-1}$ ", en homenaje al mito de referencia, $\mathrm{M}_{1}$, el mito bororo que, como se constataba de inmediato, era sólo una versión invertida y atenuada de los mitos jê que lo seguían $\left(\mathrm{M}_{7-12}\right)$. El "mito de referencia" es un mito cualquiera, un mito "sin referencias", un $m-1$, como todos los mitos. Porque todo mito es una versión de otro mito, todo otro mito se abre hacia un tercero y un cuarto mitos, y los $n-1$ mitos de la América indígena no expresan un origen ni apuntan a un destino: no tienen referencia. (Discurso sobre los orígenes, el mito es precisamente lo que esquiva el origen.) El "mito" de la referencia deja el lugar al sentido del mito, al mito como máquina de sentido: un instrumento para convertir un código en otro, proyectar un problema sobre un problema análogo, hacer "circular la referencia" (como diría Latour), contra-efectuar el sentido en forma anagramática. Recuérdese el pasaje de El hombre desnudo en que el autor generaliza las observaciones de Saussure sobre el anagrama, 
sugiriendo que ahí nos acercamos a la matriz de todo sentido, y que el mecanismo del juego de palabras (calembour) constituye el "fundamento de toda semiología" (L.-S. 1971: p. 581). (He ahí una tesis que lleva la idea de "juego de lenguaje" realmente a sus últimas consecuencias.)

La primera aproximación al concepto de mito que Lévi-Strauss ensayó destacaba su traducibilidad integral: "Podríamos definir el mito como el modo de discurso en que el valor de la fórmula traduttore, traditore tiende prácticamente a cero" (L.-S. 1955: 232). En El hombre desnudo la definición se ha extendido del plano semántico al plano pragmático: aprendemos que el mito no sólo es traducible, sino que es traducción:

todo mito es por naturaleza traducción [...] se sitúa no dentro de una lengua y dentro de una cultura o subcultura, sino en el punto de articulación de éstas con otras lenguas y otras culturas. Así el mito nunca es de su lengua, es una visión en una lengua otra (id. 1971: 576-77).

Esa definición perspectivista del mito propuesta en El hombre desnudo lo hace contiguo a la antropología misma, saber que se constituye, en una definición crucial de Lévi-Strauss avanzada ya en 1954, como la "ciencia social de lo observado". Ahora bien, si la antropología es "ciencia social de lo observado", las Mitológicas, como sabemos, son "el mito de la mitología". Esas dos definiciones son convergentes. El discurso de la antropología estructural establece las condiciones de toda antropología posible. Toda antropología es una transformación de las "antropologías" que son su objeto, situadas todas, desde siempre, en el "punto de articulación de una cultura con otras culturas". Lo que permite pasar de un mito a otro, y de una cultura a otra, es de la misma naturaleza que lo que permite pasar de los mitos a la ciencia de los mitos, y de la cultura a la ciencia de la cultura. Transversalidad y simetría. Así se abre una conexión inesperada entre el proyecto de las Mitológicas y el principio (posestructuralista) de simetría generalizada de Bruno Latour e Isabelle Stengers: la mitología estructural es una experiencia de simetrización antropológica, una operación de desenglobamiento jerárquico de las diferencias entre todos los términos analíticos. (Lo que se llama posestructuralismo es esencialmente la afirmación de una ontología de las multiplicidades planas, en que las nociones de continuidad y de homogeneidad no tienen nada más en común. Una ontología de la transversalidad, es decir, de la continuidad entre heterogéneos.) Desenglobamiento jerárquico, es decir: la diferencia entre la "cultura" (o "teoría") del antropólogo y la "cultura" (o "práctica") del nativo no es considerada como poseedora de ningún privilegio ontológico o epistemológico sobre las diferencias "internas” a cada una de esas culturas; no es más ni menos condicionante que las diferencias de ambos lados de la frontera discursiva.

Y si el mito es traducción, entonces no es, sobre todo, representación, porque una traducción no es una representación sino una transformación. "Una máscara no es lo que representa, sino sobre todo lo que transforma, es decir, lo que ha escogido no representar" (La ruta de las Máscaras).

Lo que da al metaobjeto multidimensional que son las Mitológicas un carácter propiamente holográfico, exactamente como el rizoma mítico con el que él hace rizoma, es que contiene en cada mito una imagen reducida del sistema mítico panamericano (el "mito único"). Es justamente porque la estructura está rigurosamente definida como un sistema de transformaciones, que no puede ser representada sin hacer de su representación una parte de sí misma" (Maniglier 2000: xxx). Eso nos orienta hacia una reconcepción de estructura como "transformalista", o mejor, "transformacionalista", es decir, ni formalista, ni transformacional (en el sentido chomskyano): 
Una estructura está siempre entre dos: entre dos variantes, entre dos secuencias de un mismo mito [...] La unidad de la estructura no es la de una forma que se repetiría idénticamente en una y otra variante, sino la de una matriz que permite mostrar en qué una variante es una transformación real de la otra [...] La estructura es rigurosamente coextensiva de sus actualizaciones. He ahí por qué Lévi-Strauss insiste en la diferencia entre el estructuralismo y el formalismo, que se tiende obstinadamente a pasar por alto (Maniglier op.cit: $\mathrm{xx})^{4}$

\section{VI}

Si no sin estructura, entonces, por lo menos un estructuralismo con otra noción de estructura que la de Las estructuras elementales. O tal vez deberíamos decir que hay dos usos diferentes del concepto de estructura en la obra de Lévi-Strauss: como principio trascendental de unificación, ley formal de invariancia, y como operador de divergencia, modulador de variación continua (variación de variación). La estructura como combinatoria gramatical cerrada y como multiplicidad diferencial abierta. En verdad, las dos estuvieron siempre presentes en la obra de Lévi-Strauss, pero su peso relativo cambia a lo largo del tiempo.

Volvamos ahora un paso atrás, o más bien, combinemos ese paso diacrónico con la discontinuidad sincrónica a la que aludimos más arriba. La obra de Lévi-Strauss, desde muy temprano, contiene un subtexto o un contratexto posestructuralista. La supuesta parcialidad del estructuralismo por oposiciones simétricas, equivalentes, duales, discretas y reversibles (como las del esquema totémico clásico), es desmentida no sólo por la hasta hoy sorprendente crítica al concepto de organización dualista del artículo de 1956 -que postula el ternarismo, la asimetría y la continuidad como anteriores al binarismo, a la simetría y a la discontinuidad-sino, más aún, por la igualmente antigua y aún más sorprendente "fórmula canónica del mito", que puede ser cualquier cosa menos simétrica y reversible. Además de eso, es digno de nota que Lévi-Strauss cierre las dos fases de las Mitológicas (El "Finale" de El hombre desnudo y la Histoire de Lynx) con una advertencia sobre los límites del vocabulario de la lógica extensional para dar cuenta de las transformaciones que ocurren en los mitos y entre ellos.

Sobre todo, ciertamente no es por casualidad que los dos últimos libros mitológicos de Lévi-Strauss estén construidos como desarrollos precisamente de esas dos figuras del dualismo en desequilibrio. La alfarera celosa (1985) es una ilustración sistemática de la fórmula canónica, al paso que la Histoire de Lynx se concentra en la inestabilidad dinámica -el "desequilibrio perpetuo" - de las dualidades cosmo-sociológicas amerindias. Eso me hace suponer que nos encontramos frente a una misma estructura virtual, cuya fórmula canónica, que pre-desconstruye el analogismo totémico del tipo $\mathrm{A} / \mathrm{B}=\mathrm{C} / \mathrm{D}[\mathrm{A}$ es a $\mathrm{B}$ como $\mathrm{C}$ es a D], y el dualismo dinámico, que corroe la paridad estática de las oposiciones binarias, serían solamente dos actualizaciones.

4 Por eso también la búsqueda de una "estructura del mito" en cuanto objeto sintagmático cerrado, es un perfecto contrasentido. Como destaca en esa observación de Maniglier, y aún más enfáticamente en la demostración de Mauro Almeida en el artículo ya mencionado, la transformación estructural por excelencia, la fórmula canónica del mito, no permite definir la "estructura interna" de un mito, porque no existe tal cosa. Un mito no se distingue de sus versiones, la composición "interna" de una narración es de la misma naturaleza que sus transformaciones "externas". Lo que pasa dentro de un mito es lo que permite pasar de un mito a otro. Todo mito está conformado como una "botella de Klein" (L.-S. 1985: p. 209 y sigs.).

5 La expresión “desequilibrio perpetuo" hace su primera aparición en Las estructuras elementales, para describir el casamiento avuncular de los tupí, pueblo cuya mitología es, tal vez no por casualidad, la referencia principal para el tema del desequilibrio perpetuo en Histoire de Lynx. 
Con la fórmula canónica, en lugar de una oposición simple entre metáfora totémica y metonimia sacrificial, nos instalamos de inmediato en la equivalencia entre una relación metafórica y una relación metonímica, la "torsión" que hace pasar de una metáfora a una metonimia o viceversa (L.-S. 1966: p. 211): la famosa "doble torsión", la "torsión supernumeraria", que es en realidad la sola transformación que se puede llamar propiamente "estructural": la "relación desequilibrada ... [que es] una propiedad inherente a las transformaciones míticas" (L.S. 1984: p. 13). La conversión asimétrica entre el sentido literal y el figurado, el término y la función, el continente y el contenido, lo continuo y lo discontinuo, el sistema y su exterior: ésos son los verdaderos temas estructuralistas que atraviesan todos los análisis lévi-straussianos de la mitología amerindia.

Con la Historia de Lince, el desequilibrio o la "apertura intensiva" que es una propiedad constitutiva de la estructura - de esa segunda noción de estructura- alcanza lo que podríamos llamar hegelianamente "conciencia de sí". Ya hemos observado que las Mitológicas conceden mucha importancia, incluso retórica, al imperativo de la terminación. Pero esa importancia es drásticamente relativizada por diversos pasajes de la obra que, en sentido inverso, subrayan la interminabilidad del análisis, la marcha en espiral (antes que en círculo) de las transformaciones, la asimetría de las oposiciones, la pluralidad de los niveles, las dimensiones suplementarias, la multiplicidad y diversidad de los ejes necesarios para ordenar los mitos... La palabra clave aquí es desequilibrio, obsesivamente repetida en las Mitológicas. Algunos pocos ejemplos: "el desequilibrio siempre está dado..." (L.-S. 1966: p. 222); "lejos de estar aislada de las otras, cada estructura contiene un desequilibrio que no puede ser compensado sin apelar a un término tomado en préstamo de una estructura adyacente..." (id. 1967: p. 294); "incluso cuando la estructura cambia o se enriquece para superar un desequilibrio, es siempre al precio de un nuevo desequilibrio que se revela en otro plano [...] la estructura debe a una ineluctable asimetría su poder de generar el mito, el cual no es otra cosa que un esfuerzo por corregir o disimular esa disimetría constitutiva" (id.: p. 406).

Ese desequilibrio no es una simple propiedad formal de la mitología, que responde por la transformabilidad y traducibilidad de los mitos, sino un elemento fundamental de su contenido. Los mitos piensan a través de ese desequilibrio, y lo que piensan es ese desequilibrio mismo, la disparidad en que consiste "el ser del mundo" (id. 1971: p. 539). Los mitos contienen su propia mitología, o teoría "inmanente" (id. 1964: p. 20), la teoría que afirma, según un célebre pasaje de El hombre desnudo, una

asimetría primera, que se manifiesta diversamente según la posición que se adopte para aprehenderla: entre lo alto y lo bajo, el cielo y la tierra, la tierra firme y el agua, lo cerca y lo lejos, la izquierda y la derecha, el macho y la hembra, etc. Inherente a lo real, esta disparidad pone en marcha la especulación mítica, pero porque condiciona, aun más acá del pensamiento, la existencia de todo objeto de pensamiento. (id., 1971: p. 539). 544

Pero es apenas veinte años después, con Histoire de Lynx, que el mito accederá a lo que se podría llamar su momento propiamente especulativo, cuando transforma el desequilibrio perpetuo de condición en tema:

¿Cuál es, en efecto, la inspiración profunda de estos mitos? Nuestro esquema de la página 90 lo aclara. Representan la organización progresiva del mundo y de la sociedad bajo la forma de una serie de biparticiones, pero sin que en las partes resultantes en cada etapa aparezca nunca una verdadera igualdad, de forma que, de algún modo, una es siempre superior a la otra. De ese desequilibrio dinámico depende el buen funcionamiento del sistema que, sin él, estaría constantemente amenazado de caer en un estado de inercia. Lo que proclaman implícitamente estos mitos es que los polos entre los que se ordenan los fenómenos naturales y la vida 
en sociedad -cielo y tierra, fuego y agua, alto y bajo, cerca y lejos, indios y noindios, conciudadanos y extranjeros, etc.- no pueden ser gemelos. El espíritu se afana en emparejarlos sin acceder a establecer entre ellos una paridad. Porque son esas desviaciones diferenciales en cascada, tal y como las concibe el pensamiento mítico, las que ponen en marcha la máquina del universo. (1991: 90-91). 102

Los mitos, en fin, pensándose entre sí, se piensan en cuanto tales, en un movimiento especulativo que, si "reflexiona" -es decir, se autotransforma- correctamente, no podrá escapar al desequilibrio sobre el cual reflexiona. La dualidad imperfecta en torno a la cual gira el último gran análisis mitológico de Lévi-Strauss, la gemelidad que es "la clave de todo el sistema", es la expresión acabada de esa asimetría autopropulsiva. La verdadera dualidad que interesa al estructuralismo no es el combate dialéctico entre Naturaleza y Cultura, sino la diferencia intensiva e interminable entre los gemelos desiguales de Histoire de Lynx, que son la cifra del pensamiento mítico. La cifra, en todos los sentidos de la palabra: la clave, el número y la seña. La cifra: la disparidad fundamental de la díada, la oposición como límite inferior de la diferencia, el dos como caso particular de lo múltiple.

\section{VII}

Aproximémonos a nuestra conclusión. Patrice Maniglier observaba, en relación con la diferencia entre las dos fases mayores del proyecto estructuralista, que

Si el primer momento de la obra de Lévi-Strauss parece caracterizarse por una intensa interrogación sobre el problema del pasaje de la naturaleza a la cultura, y sobre la discontinuidad entre esos dos órdenes [...] el segundo momento se caracteriza no menos intensamente por una denuncia obstinada, por parte de Lévi-Strauss, de la [tentativa de] constitución de la humanidad como un orden aparte (Maniglier 2000: 7).

En efecto, considérese el último párrafo de las Estructuras, en donde el autor observa que, en sus mitos sobre el Otro y el Más allá, "la humanidad sueña con capturar y fijar ese instante elusivo en que le fue permitido creer que podía hacer trampas con la ley del intercambio, ganando sin perder, disfrutando sin compartir", y que así para ella la felicidad completa, "eternamente negada al hombre social", es la que consiste en "vivir entre sí". Compárese esa constatación, por último tan freudiana, con un pasaje mucho más tardío de la obra de Lévi-Strauss, donde el antropólogo define el mito como "una historia del tiempo en que los humanos y los animales no se distinguían entre sí" (L.S. \& Eribon 1988: p. 193), agregando que la humanidad nunca pudo resignarse a la falta de acceso comunicativo con las demás especies del planeta. Ahora bien, la nostalgia de una comunicación originaria entre todas las especies (la continuidad interespecífica) no es exactamente lo mismo que aquella nostalgia de la vida "entre sí" responsable de la fantasía del incesto póstumo (la discontinuidad intra-específica). Muy por el contrario, diríamos que ha cambiado el énfasis, y el sentido de lo que el estructuralismo toma como siendo el contradiscurso antropológico, es decir, humano. En otras palabras, la segunda voz del discurso antropológico del estructuralismo comienza a sonar más fuerte.

La discordancia o tensión creativa entre los dos "estructuralismos" contenidos en la obra de Lévi-Strauss es internalizada de modo especialmente complejo en las Mitológicas. Ya hemos visto que Lévi-Strauss contrastaba el álgebra del parentesco de Las estructuras elementales, que estaría enteramente del lado de lo discreto, con la dialéctica mítica entre continuo y discontinuo. Esa diferencia no es puramente formal. Porque no es sólo la forma estética de la mitología amerindia lo que se muestra como una mezcla de continuo y discontinuo, sino también su contenido filosófico; y por lo demás ¿cómo podría un verdadero estructuralista separar la forma del contenido? 
Así, es preciso concluir que las Mitológicas son algo más que una empresa centrada en el "estudio de las representaciones míticas del pasaje de la naturaleza a la cultura", que es como modestamente describe el autor su empresa en Paroles Données. Pues, a medida que van siendo escritas, el autor empieza, por su lado, a contestar la pertinencia de un contraste radical entre Naturaleza y Cultura. Sería entonces un poco absurdo imaginar que LéviStrauss transfiere a los indios la insensatez que venía diagnosticando como la tara fatal del Occidente. Y en efecto, las Mitológicas, lejos de describir un pasaje claro y unívoco entre Naturaleza y Cultura, obligaron a su autor a cartografiar un laberinto de caminos tortuosos y equívocos, vías transversales, callejuelas estrechas, oscuros callejones sin salida, ríos que corren en los dos sentidos al mismo tiempo. El pasaje de sentido único entre Naturaleza y Cultura no pasa, en cierto sentido, de la primera mitad del primer libro de la tetralogía. De ahí en adelante, los siete libros de la serie completa se muestran fascinados por las "mitologías de la ambigüedad" (De la miel a las cenizas), por las "mitologías de las fluxiones" (El origen de las maneras de mesa), por los trayectos regresivos y las marchas retrógradas de la Cultura a la Naturaleza, las zonas de compenetración entre esos dos órdenes, los pequeños intervalos, las periodicidades cortas, las repeticiones rapsódicas, los modelos analógicos, las deformaciones continuas, los desequilibrios perpetuos, los dualismos que se desdoblan en semitriadismos y estallan inesperadamente en una multiplicidad de ejes transversales de transformación... La miel y la seducción sexual, el cromatismo y el veneno, la luna y la androginia, la algazara y el hedor, los eclipses y la botella de Klein, los triángulos culinarios que vistos de cerca se transforman en curvas de Koch, es decir, fractales infinitamente complejos... Se diría que el contenido de la mitología amerindia consiste en una negación del propio impulso generador del mito, en la medida en que esa mitología piensa activamente, y contempla nostálgicamente, un continuo cuya negación es, según lo entiende Lévi-Strauss, la condición fundamental del pensamiento. Si la mitología amerindia posee, como afirma varias veces Lévi-Strauss, un derecho y un revés, un sentido progresivo y otro regresivo, es también porque esos son los dos sentidos o direcciones del propio discurso estructuralista (o viceversa). La polémica distinción entre mito y ritual del "Finale" de El hombre desnudo se revela, a fin de cuentas, como habiendo sido recursivamente interiorizada: el gran mito tupí de Historia de Lince describe un movimiento idéntico al que define la esencia de todo rito, la cascada de oposiciones de objetivo decreciente, su convergencia asintótica en un esfuerzo "desesperado" por captar la asimetría última de lo real. Como si el único mito que funcionase realmente como un mito lévi-straussiano fuese "el mito de la mitología", es decir, las Mitológicas mismas. O no: tampoco ése. Éste es ciertamente un problema a retomar.

\section{VIII}

La distancia real que separa las dos grandes fases de la obra de Lévi-Strauss es un movimiento crucial realizado en las Mitológicas: la "amerindianización del estructuralismo". Las Mitológicas son un verdadero tratado de sociología indígena, en el sentido autoral de la palabra. Sociología de los indios, hecha por los indios: "la ciencia social de lo observado". Es en este sentido que completan el trabajo de disolución de la sociología, cuyas primeras señales Maniglier veía en Las estructuras elementales. Es claro que las Mitológicas son ante todo un análisis de mitos hecho por Lévi-Strauss, con una pretensión de tipo psicológicocognitivo. La propuesta del autor es examinar el funcionamiento de la imaginación mítica en cuanto facultad del espíritu humano. Sin embargo, más allá de eso, o tal vez en lugar de eso, las Mitológicas son también un estudio de etno-sociología, es decir, de antisociología. 
Existe allí una imagen del socius inscrita en ese discurso mitológico; esa imagen tiene poco en común con nuestras propias metáforas. Es interesante observar que en los mitos analizados en la serie se habla muy poco de lo que la antropología clásica entiende por "sociología". Los mitos poco dicen sobre clanes, derechos, poder político, estructuras de autoridad... hablan de sangre, miel, tabaco, podredumbre, fantasmas, puercos, canibalismo, colores de los pájaros, penes removibles, anos personificados... En suma, los mitos hablan de un universo esencialmente material, corporal, sensible y sensorial, y muy poco de un universo jurídico y normativo, que es como estamos acostumbrados a concebir el discurso sociológico. Las Mitológicas demuestran que la sociología indígena es una sociología de los cuerpos y de los flujos materiales. De hecho, esos libros son como una lucha cerrada entre la unidad del espíritu humano y la multiplicidad del cuerpo indígena. El espíritu comienza con una clara ventaja, en la Obertura de Lo crudo y lo cocido; pero el cuerpo va progresivamente dominando en la lucha, hasta ganarla de forma inequívoca, aunque por puntos, por un pequeño clinamen que se acentúa rápidamente en los rounds finales, con Histoire de Lynx.

La idea de una amerindianización del estructuralismo es, en mi opinión, esencial para que la reanudación de la herencia intelectual de Lévi-Strauss se haga en la forma de un progreso epistemológico, es decir, político, y no de un retorno nostálgico a un pretendido rigor científico que la antropología posmoderna habría abandonado. Debemos ser capaces de eliminar todas las consecuencias de la idea de que el estructuralismo, pensamiento auténticamente especulativo o autotemático, es una transformación estructural del pensamiento amerindio: más bien es la resultante de la inflexión que este último pensamiento recibe al ser filtrado por problemas y conceptos característicos de la logopoiesis occidental (el mismo y el otro, lo continuo y lo discreto, lo sensible y lo inteligible, la naturaleza y la cultura...), según un movimiento de "equivocación controlada", en equilibrio inestable, siempre fecundamente amenazado por la traición y por la corrupción. Entiendo que es tan poco avisado separar la antropología de Lévi-Strauss de sus condiciones de constitución en contacto con la lingüística de Saussure o con la morfología de D’Arcy Thompson, como lo sería separarlo de la experiencia formativa del autor, en el campo y en las bibliotecas, junto a los pueblos amerindios. No es posible ignorar los "cimientos indoamericanos del estructuralismo", para decirlo con A.-C. Taylor (2004: p. 97), sin perder con ello una dimensión vital de comprensión de la obra entera de Lévi-Strauss. Eso no significa de ninguna manera que la validez de los problemas y los conceptos propuestos por este antropólogo se limite a un "área cultural", por vasta que sea, sino justamente lo contrario: la obra de Lévi-Strauss es el momento en que el pensamiento indoamericano arroja los dados, émet son coup de dés, superando su propio "contexto" y mostrándose capaz de "dar qué pensar a otro" es decir, a todo aquel que, persa o francés, se disponga a pensar, sin más.

Esta es la mayor lección del maestro: nos hemos hecho capaces de oír otras lecciones, las lecciones del otro, de practicar esa "apertura al Otro" que, por una voltereta sorprendente, la antropología descubre ser la actitud que caracteriza, mucho más que a nosotros mismos, a esos otros que estudia, esos otros que antes se complacía en imaginar encerrados en su intemporal capullo etnocéntrico. El mensaje final de Historia de Lince es entonces aquel, perturbador, de que el otro de los otros también es otro. Y la conclusión más general a extraer es que la antropología no dispone de otra posición posible que el establecimiento de una coplanaridad de principio con el pensamiento salvaje, el trazar un plano de inmanencia en común con su objeto. Al definir las Mitológicas como el "mito de la mitología" y el conocimiento antropológico como una transformación de la praxis indígena, la antropología 
lévi-straussiana proyecta una "filosofía por venir", marcada positivamente por el sello de la interminabilidad y de la virtualidad.

Después de la recuperación del evolucionismo por la psico-antropología cognitiva, esa ciencia perpetuamente prometedora; después del resurgimiento del difusionismo con la sociología crítica de la "invención de la tradición”; después del regreso (¿pero se había ido realmente?) del funcionalismo con la economía política de la globalización, bueno, tal vez haya llegado la hora de desolvidar y recomplicar -como decía Leach, de "repensar"- el estructuralismo, la ciencia social de lo observado. El estructuralismo, o el Anti-Narciso.

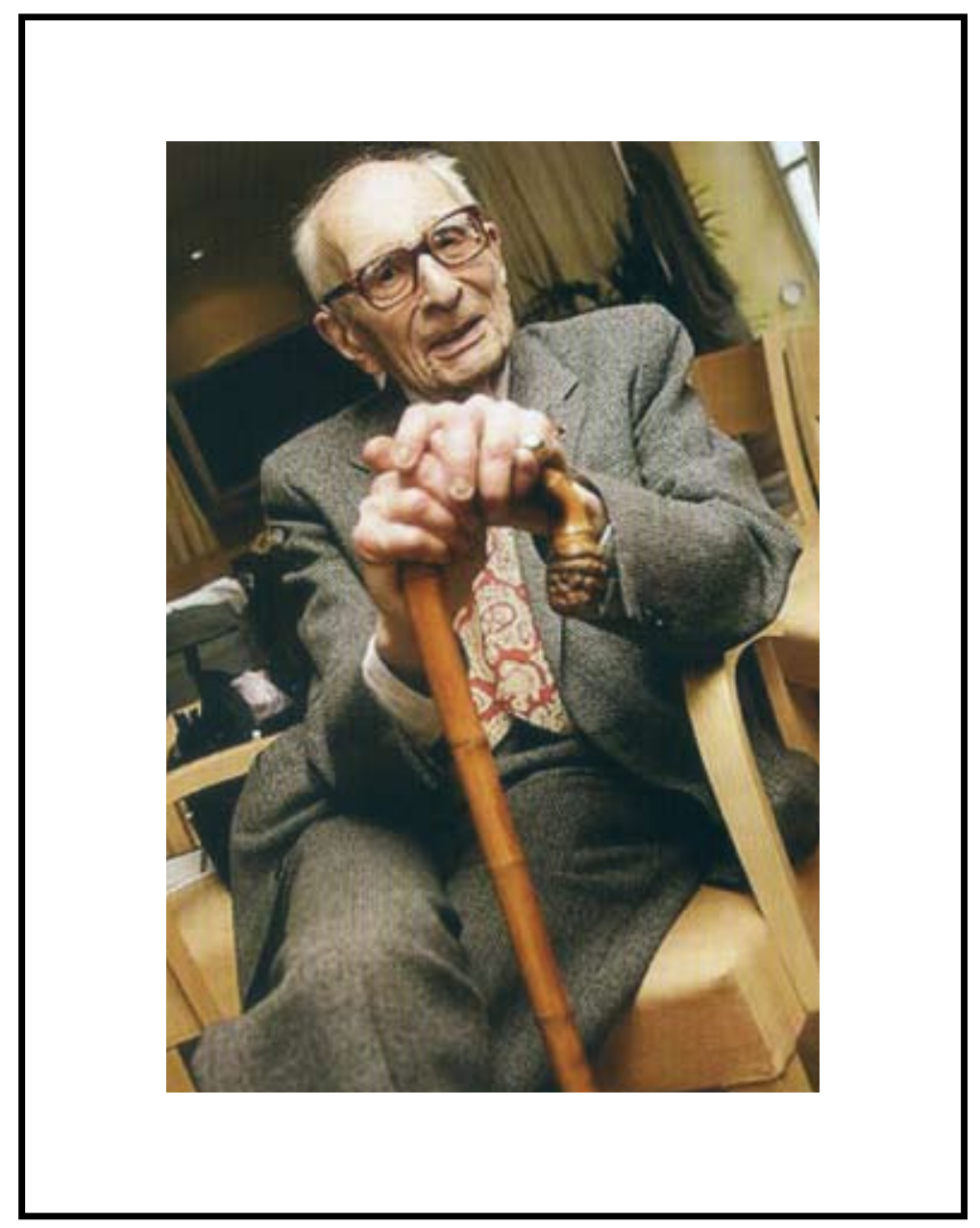

Claude Lévi - Strauss a los 100 años de edad. 